\title{
Reward Processing
}

David V. Smith \& Mauricio R. Delgado

Department of Psychology, Rutgers University, Newark, NJ 07102.

Please cite this article using the information below:

Smith, D. V., \& Delgado, M. R. (2015). Reward Processing. In A. W. Toga (Ed.), Brain Mapping: An Encyclopedic Reference (1 ed., Vol. 3, pp. 361-366). Waltham, MA: Academic Press. doi: 10.1016/B978-0-12-397025-1.00255-4

For a PDF reprint of the printed version of the chapter, please contact DVS (smith@psychology.rutgers.edu) or MRD (delgado@psychology.rutgers.edu). 


\section{Synopsis}

Our behavior is inextricably linked to rewards in our environment. This observation has sparked considerable interest in understanding the neural mechanisms that support reward processing in humans. Early neuroimaging studies implicated regions such as the striatum and ventromedial prefrontal cortex (VMPFC) in reward processing, particularly how activation in these regions is modulated by anticipation and receipt of rewards. These findings have been extended in the context of models that account for the representation of subjective value, which influences decision making. Building from these findings, researchers are now beginning to characterize how social information has idiosyncratic influences on reward processing.

\section{Introduction}

Our decisions frequently require us to evaluate and compare available rewards in the environment. Broadly defined, rewards are stimuli of positive valence that have the potential to influence behavior (for additional information, see $§ 58$ Reward). Refining this definition, animal learning theory notes that rewards function to promote learning, encourage approach and consummatory behavior for acquiring reward items, and induce positive emotions (Berridge \& Robinson, 1998; Robbins \& Everitt, 1996; Schultz, 2006). Notably, deficits in these functions are hallmarks in several psychopathologies ranging from schizophrenia (Gold et al., 2012) to depression (Pizzagalli et al., 2009) (for additional information, see $\$ 116$ Schizophrenia, and §119 Depression). Thus, understanding the neural mechanisms supporting reward processing has been a long-standing objective in neuroscience. Although considerable progress toward this objective has been made using a wide range of methodologies and approaches-including single-unit neurophysiology (Hayden et al., 2009; Sugrue et al., 2005), optogenetics (Stuber et al., 2012), and brain stimulation (Amemori \& Graybiel, 2012; Boggio et al., 2010)—this chapter will primarily focus on findings from human neuroimaging work.

To investigate reward processing, researchers have employed concrete rewards such as money (Delgado et al., 2000; Knutson et al., 2001) and food (Kringelbach et al., 2003; Small et al., 2001), as well as more abstract rewards such as social status (Ly et al., 2011) and attractive faces (O'Doherty et al., 2003a; Winston et al., 2007). Yet, we note that some reward processing studies have utilized aversive outcomes (e.g., an electric shock) that subjects aim to avoid (Delgado et al., 2009; Kim et al., 2006). Though interesting in its own right, the rewarding properties of avoiding aversive outcomes is beyond the scope of this chapter, so we refer readers to relevant reviews (Bromberg-Martin et al., 2010; Delgado et al., 2008a; Seymour et al., 2007b). The bulk of studies reviewed in this chapter will be limited to stimuli with a clear positive valence that can be easily studied in within the constraints of the neuroimaging environment using human subjects.

Studies of reward processing have implicated a diverse set of brain regions, particularly the ventromedial prefrontal cortex (VMPFC) and striatum. Indeed, a large-scale automated meta-analysis (Yarkoni et al., 2011) of 203 neuroimaging studies demonstrates a selective association between the term "reward" and activation in VMPFC and striatum (Figure 1). Although these regions are likely fundamental to reward processing, we note 
that other studies have found links between activation in amygdala (Jenison et al., 2011; Morrison \& Salzman, 2010), midbrain (Ballard et al., 2011; Carter et al., 2009; D'Ardenne et al., 2008), and parietal cortex (Klein et al., 2008; Platt \& Glimcher, 1999). The putative reward circuit in humans therefore involves several regions, chief among them are the VMPFC and striatum. Accordingly, many of the studies reviewed in this chapter will focus on VMPFC and striatum due to a larger wealth of data on reward processing and these regions.

\section{Foundations of Reward Processing}

Early investigations of reward processing were spurred by the observation that rats would work vigorously — often while sacrificing food-to electrically self stimulate near the ventral striatum (Olds \& Milner, 1954). Similar observations were made in human subjects, who reported sensations of pleasure upon receiving electrical stimulation to an area near the ventral striatum (Bishop et al., 1963). These studies suggested that dopamine, a neuromodulator originating in the midbrain and projecting to the striatum (Haber \& Knutson, 2010), might be inextricably be linked to reward processing. This idea inspired pharmacological work that directly manipulated the levels of dopamine in rodents. Strikingly, researchers observed that animals deficient in dopamine showed attenuated reward-related responses, such as reduced response rates and diminished interested in food and sex (Wise et al., 1978). Although these observations led to popular accounts of dopamine functioning as a "pleasure chemical", some work has questioned whether dopamine is even necessary for reward processing or the experience of pleasure (Cannon \& Bseikri, 2004). Furthermore, subsequent studies have indicated that dopamine serves wider functions related to motivated behavior, including altering the salience of incentives (Berridge \& Robinson, 1998) and updating models of reward prediction (Schultz \& Dickinson, 2000).

Adapting behavior based on models of predicted rewards serves as an important function of reward processing, as it affords an opportunity to maximize future rewards. Reward prediction errors (RPEs) occur when a stimulus alters our expectations of the content of future rewards (Schultz, 2000; Schultz \& Dickinson, 2000) (for additional information, see $\$ 257$ Reinforcement Learning). To investigate the neuronal basis of RPE signals, Schultz and colleagues (Schultz et al., 1997) utilized single-unit recordings and measured how midbrain activity changed in response to a cue that predicted a reward. At the beginning of the experiment, prior to learning the cue-reward association, midbrain neurons exhibited increased firing rates in response to the unexpected reward but not the cue. Over time, as the cue-reward association became stronger, cue-evoked activity increased while reward-evoked activity diminished. Once the cue-reward association became fully established, the omission of a predicted reward led to diminished midbrain activity. Based on these findings, Schultz and colleagues put forth the hypothesis that dopaminergic neurons within midbrain encoded RPE signals (Schultz, et al., 1997). Similar RPE signals have been observed to correlate with activity in areas that receive dopaminergic projections from the midbrain, such as the VMPFC (Ramnani et al., 2004; Rutledge et al., 2010) and striatum (O'Doherty et al., 2003b; Rutledge, et al., 2010). 
Although the relationship between RPE signals and key dopaminergic areas such as VMPFC and striatum is now well established, other work has suggested additional reward processing functions for these regions, particularly the anticipation of and receipt of rewards. To examine how the brain encodes the anticipation of and receipt of rewards, Knutson and colleagues (Knutson, et al., 2001) developed a response-time task (the Monetary Incentive Delay or MID task). On a typical trial of the MID, subjects first see a cue indicating the type and magnitude of a reward (e.g., \$5). Then, after a brief and variable anticipatory period, a target appears. If the subject responds to the target quickly enough, the reward is delivered. This approach yielded two core results: reward anticipation increased in ventral striatum while reward receipt increased activation in VMPFC (Knutson et al., 2003).

Other studies of reward processing have utilized alternative task structures, including active decision making such as gambling games (Breiter et al., 2001; Delgado, et al., 2000; Elliott et al., 2000). For example, Delgado and colleagues (Delgado, et al., 2000) created a simple card-guessing task in which each trial asks the subject to guess whether an upcoming card will be higher or lower than the number 5 . Correct guesses earn a monetary reward whereas incorrect guesses result in a monetary punishment. Using this simple structure, Delgado and colleagues found that monetary rewards compared to punishments evoke activation in the striatum (Delgado, et al., 2000). As these observations could reflect the affective qualities of reward, Tricomi and colleagues (Tricomi et al., 2004) investigated whether the reward-related signal observed in the dorsal striatum is due to the hedonic aspect of a reward outcome or the reinforcement of the action that led to the reward outcome. Crucially, their results indicated that reward-related outcome responses in the dorsal striatum, in particular, are dependent on action, indicating a link between striatal activation and reinforcement. Extending these observations, other researchers have applied reinforcement learning models to striatal activation, noting distinct roles for ventral and dorsal striatum, with the former participating in the prediction of future rewards and the latter maintain representations action-outcome contingencies $(0$ 'Doherty et al., 2004). Yet, even in the absence of learning, other work has highlighted an important role for motivation in striatal activation (Clithero et al., 2011; Delgado et al., 2004). Taken together, these finding highlight the complexity of striatal reward-related responses, as they represent multiple signals related to value, motivation, and learning (e.g., RPE).

Although much of the work on reward processing in humans has utilized monetary incentives, a host of research point to the general nature of the reward processing system. Activation in striatum and VMPFC is modulated by various sensations, including the taste of chocolate (Small, et al., 2001) and juice (Kim et al., 2011), pleasant smells (Gottfried et al., 2002), touch (Rolls et al., 2003), and viewing attractive faces (Aharon et al., 2001; 0'Doherty, et al., 2003a), and even the texture of fat in the mouth (Grabenhorst et al., 2010). These findings also generalize to abstract rewards such as humor (Mobbs et al., 2003; Watson et al., 2007), art (Vartanian \& Goel, 2004), charitable giving (Moll et al., 2006), the experience of romantic love (Acevedo et al., 2012; Aron et al., 2005) and other social stimuli (Fehr \& Camerer, 2007). These observations highlight the general nature and flexibility of the reward circuit, potentially hinting at its significance in shaping behavior in response to diverse stimuli and events. 


\section{Encoding the Subjective Value of Rewards}

The observation that multiple rewards evoke similar activation within the striatum and VMPFC may hint at a mechanism for flexibly comparing disparate rewards on a common scale (Grabenhorst \& Rolls, 2011; Montague \& Berns, 2002). Understanding the neural mechanisms underlying this computation has been a cardinal goal of decision neuroscience (Padoa-Schioppa, 2011; Rangel et al., 2008; Smith \& Huettel, 2010) (for additional information, see $§ 258$ Value Representation and $\$ 262$ Economic Decision Making). To address this goal, several studies have now converged on the observation that VMPFC (Chib et al., 2009; FitzGerald et al., 2009; Kim, et al., 2011; Lin et al., 2012) and striatum (Clithero, et al., 2011; Izuma et al., 2008) contain spatially overlapping rewardrelated signals for multiple reward types (e.g., money, food, social images, and consumer goods). These findings have also been confirmed by meta-analytic techniques aggregating data across multiple studies (Clithero \& Rangel, 2014).

Though suggestive of a mechanism for representing different goods on a common scale, these studies do not consider how individual differences preferences between rewards relates to activation differences for those rewards. If a brain region-whether VMPFC or striatum-encodes a reward signal on a common scale, researchers have hypothesized that activation within that region (or regions) should predict an individual's subjective value for those rewards (Levy \& Glimcher, 2012). Using this general approach, recent research has suggested that activation within VMPFC encodes different rewards on a common scale in which idiosyncratic subjective values (e.g., how much money an individual is willing to spend for a reward) are matched to neural value signals (e.g., the difference in activation magnitude for the good and money) within VMPFC (Levy \& Glimcher, 2011; Smith et al., 2010; Zaki et al., 2014). Extending these observations, recent work has also noted that state-dependent changes in subjective value predict statedependent changes in VMPFC activation (Libedinsky et al., 2011). Collectively, these studies suggest that portions of VMPFC compute reward-related signals on a common scale that predicts the subjective value of rewards (Levy \& Glimcher, 2012).

\section{Modulation of Reward Processing by Social Information}

Reward-related signals computed in VMPFC and striatum are subject to modulation by multiple factors, including bodily states of satiety (Gottfried et al., 2003), time (Kable \& Glimcher, 2007), and social information (Behrens et al., 2008). The effect of social information on reward processing is greatly facilitated by human neuroimaging studies, as they allow for real-time interaction between subjects. Using this approach, King-Casas and colleagues observed that signals to trust a partner are encoded like RPEs such that, over time, learning that a partner predicts reward shifts dorsal striatum from the receipt of a monetary reward to the social interaction with the partner (King-Casas et al., 2005). Multiple studies have now demonstrated that reward-related signals in striatum can be modulated social factors related to competition (Delgado et al., 2008b; van den Bos et al., 2013) and sharing with a close friend (Fareri et al., 2012). These findings further highlight the complexity of reward-related signals within striatum, adding to evidence that striatal signals are not solely due to learning, as they can be modulated by factors unrelated to learning and reinforcement (e.g., level of closeness between participants). 
To understand the neural mechanisms underlying this modulatory influence, researchers have employed functional connectivity techniques, which quantify how the temporal correlation between distal brain regions changes depending on the psychological task (e.g., gaining or losing money) (Friston et al., 1997) (for additional information, see \$212 Functional Connectivity). One key hypothesis asserts that regions modulated by social cognitive processes (Behrens et al., 2009; Saxe, 2006) (for additional information, see $\S 172$ Social Cognition During Social Interactions), particularly the temporal-parietal junction (Carter et al., 2012), should exhibit increased functional connectivity with regions modulated by reward processing. Supporting this prediction, recent research has shown that functional connectivity between VMPFC and regions within the inferior parietal lobe, including the TPJ, increases during empathy (Janowski et al., 2013), charitable donations (Hare et al., 2010), attractive judgments (Smith et al., 2014), and social competition (van den Bos, et al., 2013). However, it should be noted that functional connectivity techniques cannot test for directionality. Thus, in these studies, it remains unclear whether signals in TPJ are directly influencing reward-related signals in VMPFC. Nevertheless, these observations provide a promising avenue for understanding how reward processing can be modulated by social information.

\section{Conclusions and Future Challenges}

The study of human reward processing has consistently demonstrated that the striatum and VMPFC are core components of our reward circuitry. Our understanding of this circuitry has rapidly evolved over the past decade. Early demonstrations of how the anticipation of and receipt of rewards modulates activation in the VMPFC and striatum have now developed into complex models of subjective value that shape idiosyncratic choice behavior. Researchers are also beginning to understand how social information impacts reward processing, potentially through functional interactions with regions outside typical reward circuitry.

Despite this progress, several challenges remain. For example, some researchers argue that reward and attention are frequently confounded, thus creating interpretative challenges for reward-related signals (Maunsell, 2004). In addition, previous reports have led to conflicting results on whether striatum encodes salience (Jensen et al., 2007; Zink et al., 2006), valence (Delgado, et al., 2000; Seymour et al., 2007a), or both (Cooper \& Knutson, 2008; Litt et al., 2011). Recent work has also suggested that reward-related signals are distributed throughout the gray matter (Vickery et al., 2011). These issues underscore the importance of examining different components of reward that are typically conflated in most paradigms. For example, most rewarding events carry affective properties that signal valence (e.g., whether the outcome was good or bad) and informative properties that signal how to maximize future rewards (e.g., repeat this action to get another reward). Indeed, recent research has highlighted how information in itself evokes activation in the reward circuitry (Bromberg-Martin \& Hikosaka, 2011; Tricomi \& Fiez, 2012). Parsing reward into different subcomponents (e.g., affective and informative) may facilitate translational work that seeks to ameliorate dysfunctional reward processing in psychopathologies (Treadway \& Zald, 2013). Taken together, these challenges-and their 
potential remedies-pave the way for years of fruitful studies on the mechanisms of reward processing.

\section{Figure Caption}

\section{Figure 1: Brain Regions Involved in Reward Processing}

A large-scale meta-analysis of 203 studies using the term "reward" reveal a strong association between activation in the ventromedial prefrontal cortex (VMPFC) and striatum. Activation in these regions is thus highly predictive of reward. Image is thresholded at whole-brain corrected (false discovery rate) at $\mathrm{p}<0.05$.

\section{Acknowledgments}

This research was supported by funding from the National Institutes of Mental Health (R01MH084081).

\section{References}

Acevedo, B. P., Aron, A., Fisher, H. E., \& Brown, L. L. (2012). Neural Correlates of Long-Term Intense Romantic Love. Social Cognitive and Affective Neuroscience, 7(2), 145-159. doi: 10.1093/scan/nsq092

Aharon, I., Etcoff, N., Ariely, D., Chabris, C. F., O'Connor, E., \& Breiter, H. C. (2001). Beautiful Faces Have Variable Reward Value: Fmri and Behavioral Evidence. Neuron, 32(3), 537-551.

Amemori, K., \& Graybiel, A. M. (2012). Localized Microstimulation of Primate Pregenual Cingulate Cortex Induces Negative Decision-Making. Nature Neuroscience, 15(5), 776-785. doi: 10.1038/nn.3088

Aron, A., Fisher, H., Mashek, D. J., Strong, G., Li, H., \& Brown, L. L. (2005). Reward, Motivation, and Emotion Systems Associated with Early-Stage Intense Romantic Love. Journal of Neurophysiology, 94(1), 327-337. doi: 10.1152/jn.00838.2004

Ballard, I. C., Murty, V. P., Carter, R. M., MacInnes, J. J., Huettel, S. A., \& Adcock, R. A. (2011). Dorsolateral Prefrontal Cortex Drives Mesolimbic Dopaminergic Regions to Initiate Motivated Behavior. Journal of Neuroscience, 31(28), 10340-10346. doi: 10.1523/JNEUROSCI.0895-11.2011

Behrens, T. E., Hunt, L. T., \& Rushworth, M. F. (2009). The Computation of Social Behavior. Science, 324(5931), 1160-1164. doi: 10.1126/science.1169694

Behrens, T. E., Hunt, L. T., Woolrich, M. W., \& Rushworth, M. F. (2008). Associative Learning of Social Value. Nature, 456(7219), 245-249. doi: 10.1038/nature07538

Berridge, K. C., \& Robinson, T. E. (1998). What Is the Role of Dopamine in Reward: Hedonic Impact, Reward Learning, or Incentive Salience? Brain Research: Brain Research Reviews, 28(3), 309-369.

Bishop, M. P., Elder, S. T., \& Heath, R. G. (1963). Intracranial Self-Stimulation in Man. Science, 140(3565), 394-396. doi: 10.1126/science.140.3565.394 
Boggio, P. S., Campanha, C., Valasek, C. A., Fecteau, S., Pascual-Leone, A., \& Fregni, F. (2010). Modulation of Decision-Making in a Gambling Task in Older Adults with Transcranial Direct Current Stimulation. European Journal of Neuroscience, 31(3), 593-597. doi: 10.1111/j.1460-9568.2010.07080.x

Breiter, H. C., Aharon, I., Kahneman, D., Dale, A., \& Shizgal, P. (2001). Functional Imaging of Neural Responses to Expectancy and Experience of Monetary Gains and Losses. Neuron, 30(2), 619-639.

Bromberg-Martin, E. S., \& Hikosaka, O. (2011). Lateral Habenula Neurons Signal Errors in the Prediction of Reward Information. Nature Neuroscience, 14(9), 1209-1216. doi: 10.1038/nn.2902

Bromberg-Martin, E. S., Matsumoto, M., \& Hikosaka, O. (2010). Dopamine in Motivational Control: Rewarding, Aversive, and Alerting. Neuron, 68(5), 815-834. doi: 10.1016/j.neuron.2010.11.022

Cannon, C. M., \& Bseikri, M. R. (2004). Is Dopamine Required for Natural Reward? Physiology and Behavior, 81(5), 741-748.

Carter, R. M., Bowling, D. L., Reeck, C., \& Huettel, S. A. (2012). A Distinct Role of the Temporal-Parietal Junction in Predicting Socially Guided Decisions. Science, 337(6090), 109-111. doi: 10.1126/science.1219681

Carter, R. M., Macinnes, J. J., Huettel, S. A., \& Adcock, R. A. (2009). Activation in the Vta and Nucleus Accumbens Increases in Anticipation of Both Gains and Losses. Frontiers in Behavioral Neuroscience, 3, 21. doi: 10.3389/neuro.08.021.2009

Chib, V. S., Rangel, A., Shimojo, S., \& O'Doherty, J. P. (2009). Evidence for a Common Representation of Decision Values for Dissimilar Goods in Human Ventromedial Prefrontal Cortex. Journal of Neuroscience, 29(39), 12315-12320. doi: 10.1523/JNEUROSCI.2575-09.2009

Clithero, J. A., \& Rangel, A. (2014). Informatic Parcellation of the Network Involved in the Computation of Subjective Value. Social Cognitive and Affective Neuroscience, 9(9), 1289-1302. doi: 10.1093/scan/nst106

Clithero, J. A., Reeck, C., Carter, R. M., Smith, D. V., \& Huettel, S. A. (2011). Nucleus Accumbens Mediates Relative Motivation for Rewards in the Absence of Choice. Frontiers in Human Neuroscience, 5, 87. doi: 10.3389/fnhum.2011.00087

Cooper, J. C., \& Knutson, B. (2008). Valence and Salience Contribute to Nucleus Accumbens Activation. Neuroimage, 39(1), 538-547. doi: 10.1016/j.neuroimage.2007.08.009

D'Ardenne, K., McClure, S. M., Nystrom, L. E., \& Cohen, J. D. (2008). Bold Responses Reflecting Dopaminergic Signals in the Human Ventral Tegmental Area. Science, 319(5867), 1264-1267. doi: 10.1126/science.1150605

Delgado, M. R., Jou, R. L., Ledoux, J. E., \& Phelps, E. A. (2009). Avoiding Negative Outcomes: Tracking the Mechanisms of Avoidance Learning in Humans During Fear Conditioning. Frontiers in Behavioral Neuroscience, 3, 33. doi: 10.3389/neuro.08.033.2009

Delgado, M. R., Li, J., Schiller, D., \& Phelps, E. A. (2008a). The Role of the Striatum in Aversive Learning and Aversive Prediction Errors. Philosophical Transactions of the Royal Society of London. Series B: Biological Sciences, 363(1511), 3787-3800. doi: 10.1098/rstb.2008.0161 
Delgado, M. R., Nystrom, L. E., Fissell, C., Noll, D. C., \& Fiez, J. A. (2000). Tracking the Hemodynamic Responses to Reward and Punishment in the Striatum. Journal of Neurophysiology, 84(6), 3072-3077.

Delgado, M. R., Schotter, A., Ozbay, E. Y., \& Phelps, E. A. (2008b). Understanding Overbidding: Using the Neural Circuitry of Reward to Design Economic Auctions. Science, 321(5897), 1849-1852. doi: 10.1126/science.1158860

Delgado, M. R., Stenger, V. A., \& Fiez, J. A. (2004). Motivation-Dependent Responses in the Human Caudate Nucleus. Cerebral Cortex, 14(9), 1022-1030. doi: $10.1093 /$ cercor/bhh062

Elliott, R., Friston, K. J., \& Dolan, R. J. (2000). Dissociable Neural Responses in Human Reward Systems. Journal of Neuroscience, 20(16), 6159-6165. doi: 20/16/6159 [pii]

Fareri, D. S., Niznikiewicz, M. A., Lee, V. K., \& Delgado, M. R. (2012). Social Network Modulation of Reward-Related Signals. Journal of Neuroscience, 32(26), 9045-9052. doi: 10.1523/JNEUROSCI.0610-12.2012

Fehr, E., \& Camerer, C. F. (2007). Social Neuroeconomics: The Neural Circuitry of Social Preferences. Trends Cogn Sci, 11(10), 419-427. doi: 10.1016/j.tics.2007.09.002

FitzGerald, T. H., Seymour, B., \& Dolan, R. J. (2009). The Role of Human Orbitofrontal Cortex in Value Comparison for Incommensurable Objects. Journal of Neuroscience, 29(26), 8388-8395. doi: 10.1523/JNEUROSCI.0717-09.2009

Friston, K. J., Buechel, C., Fink, G. R., Morris, J., Rolls, E., \& Dolan, R. J. (1997). Psychophysiological and Modulatory Interactions in Neuroimaging. Neuroimage, 6(3), 218-229. doi: 10.1006/nimg.1997.0291

Gold, J. M., Waltz, J. A., Matveeva, T. M., Kasanova, Z., Strauss, G. P., Herbener, E. S., Collins, A. G., \& Frank, M. J. (2012). Negative Symptoms and the Failure to Represent the Expected Reward Value of Actions: Behavioral and Computational Modeling Evidence. Archives of General Psychiatry, 69(2), 129-138. doi: 10.1001/archgenpsychiatry.2011.1269

Gottfried, J. A., O'Doherty, J., \& Dolan, R. J. (2002). Appetitive and Aversive Olfactory Learning in Humans Studied Using Event-Related Functional Magnetic Resonance Imaging. Journal of Neuroscience, 22(24), 10829-10837. doi: 22/24/10829 [pii]

Gottfried, J. A., O'Doherty, J., \& Dolan, R. J. (2003). Encoding Predictive Reward Value in Human Amygdala and Orbitofrontal Cortex. Science, 301(5636), 1104-1107. doi: 10.1126/science.1087919

Grabenhorst, F., \& Rolls, E. T. (2011). Value, Pleasure and Choice in the Ventral Prefrontal Cortex. Trends Cogn Sci, 15(2), 56-67. doi: 10.1016/j.tics.2010.12.004

Grabenhorst, F., Rolls, E. T., Parris, B. A., \& d'Souza, A. A. (2010). How the Brain Represents the Reward Value of Fat in the Mouth. Cerebral Cortex, 20(5), 1082-1091. doi: $10.1093 /$ cercor/bhp169

Haber, S. N., \& Knutson, B. (2010). The Reward Circuit: Linking Primate Anatomy and Human Imaging. Neuropsychopharmacology, 35(1), 4-26. doi: 10.1038/npp.2009.129

Hare, T. A., Camerer, C. F., Knoepfle, D. T., \& Rangel, A. (2010). Value Computations in Ventral Medial Prefrontal Cortex During Charitable Decision Making Incorporate Input from Regions Involved in Social Cognition. Journal of Neuroscience, 30(2), 583590. doi: 10.1523/JNEUROSCI.4089-09.2010 
Hayden, B. Y., Pearson, J. M., \& Platt, M. L. (2009). Fictive Reward Signals in the Anterior Cingulate Cortex. Science, 324(5929), 948-950. doi: 10.1126/science.1168488

Izuma, K., Saito, D. N., \& Sadato, N. (2008). Processing of Social and Monetary Rewards in the Human Striatum. Neuron, 58(2), 284-294. doi: 10.1016/j.neuron.2008.03.020

Janowski, V., Camerer, C., \& Rangel, A. (2013). Empathic Choice Involves Vmpfc Value Signals That Are Modulated by Social Processing Implemented in Ipl. Social Cognitive and Affective Neuroscience, 8(2), 201-208. doi: 10.1093/scan/nsr086

Jenison, R. L., Rangel, A., Oya, H., Kawasaki, H., \& Howard, M. A. (2011). Value Encoding in Single Neurons in the Human Amygdala During Decision Making. Journal of Neuroscience, 31(1), 331-338. doi: 10.1523/JNEUROSCI.4461-10.2011

Jensen, J., Smith, A. J., Willeit, M., Crawley, A. P., Mikulis, D. J., Vitcu, I., \& Kapur, S. (2007). Separate Brain Regions Code for Salience Vs. Valence During Reward Prediction in Humans. Human Brain Mapping, 28(4), 294-302. doi: 10.1002/hbm.20274

Kable, J. W., \& Glimcher, P. W. (2007). The Neural Correlates of Subjective Value During Intertemporal Choice. Nature Neuroscience, 10(12), 1625-1633. doi: $10.1038 / \mathrm{nn} 2007$

Kim, H., Shimojo, S., \& O'Doherty, J. P. (2006). Is Avoiding an Aversive Outcome Rewarding? Neural Substrates of Avoidance Learning in the Human Brain. PLoS Biology, 4(8), 1453-1461.

Kim, H., Shimojo, S., \& O'Doherty, J. P. (2011). Overlapping Responses for the Expectation of Juice and Money Rewards in Human Ventromedial Prefrontal Cortex. Cerebral Cortex, 21(4), 769-776. doi: 10.1093/cercor/bhq145

King-Casas, B., Tomlin, D., Anen, C., Camerer, C. F., Quartz, S. R., \& Montague, P. R. (2005). Getting to Know You: Reputation and Trust in a Two-Person Economic Exchange. Science, 308(5718), 78-83. doi: 10.1126/science.1108062

Klein, J. T., Deaner, R. O., \& Platt, M. L. (2008). Neural Correlates of Social Target Value in Macaque Parietal Cortex. Current Biology, 18(6), 419-424. doi: 10.1016/j.cub.2008.02.047

Knutson, B., Adams, C. M., Fong, G. W., \& Hommer, D. (2001). Anticipation of Increasing Monetary Reward Selectively Recruits Nucleus Accumbens. Journal of Neuroscience, 21(16), RC159.

Knutson, B., Fong, G. W., Bennett, S. M., Adams, C. M., \& Hommer, D. (2003). A Region of Mesial Prefrontal Cortex Tracks Monetarily Rewarding Outcomes: Characterization with Rapid Event-Related Fmri. Neuroimage, 18(2), 263-272.

Kringelbach, M. L., O'Doherty, J., Rolls, E. T., \& Andrews, C. (2003). Activation of the Human Orbitofrontal Cortex to a Liquid Food Stimulus Is Correlated with Its Subjective Pleasantness. Cerebral Cortex, 13(10), 1064-1071.

Levy, D. J., \& Glimcher, P. W. (2011). Comparing Apples and Oranges: Using Reward-Specific and Reward-General Subjective Value Representation in the Brain. Journal of Neuroscience, 31(41), 14693-14707. doi: 10.1523/JNEUROSCI.2218-11.2011

Levy, D. J., \& Glimcher, P. W. (2012). The Root of All Value: A Neural Common Currency for Choice. Current Opinion in Neurobiology, 22(6), 1027-1038. doi: 10.1016/j.conb.2012.06.001

Libedinsky, C., Smith, D. V., Teng, C. S., Namburi, P., Chen, V. W., Huettel, S. A., \& Chee, M. W. (2011). Sleep Deprivation Alters Valuation Signals in the Ventromedial Prefrontal Cortex. Frontiers in Behavioral Neuroscience, 5, 70. doi: 10.3389/fnbeh.2011.00070 
Lin, A., Adolphs, R., \& Rangel, A. (2012). Social and Monetary Reward Learning Engage Overlapping Neural Substrates. Social Cognitive and Affective Neuroscience, 7(3), 274-281. doi: 10.1093/scan/nsr006

Litt, A., Plassmann, H., Shiv, B., \& Rangel, A. (2011). Dissociating Valuation and Saliency Signals During Decision-Making. Cerebral Cortex, 21(1), 95-102. doi: 10.1093/cercor/bhq065

Ly, M., Haynes, M. R., Barter, J. W., Weinberger, D. R., \& Zink, C. F. (2011). Subjective Socioeconomic Status Predicts Human Ventral Striatal Responses to Social Status Information. Current Biology, 21(9), 794-797. doi: 10.1016/j.cub.2011.03.050

Maunsell, J. H. (2004). Neuronal Representations of Cognitive State: Reward or Attention? Trends Cogn Sci, 8(6), 261-265. doi: 10.1016/j.tics.2004.04.003

Mobbs, D., Greicius, M. D., Abdel-Azim, E., Menon, V., \& Reiss, A. L. (2003). Humor Modulates the Mesolimbic Reward Centers. Neuron, 40(5), 1041-1048.

Moll, J., Krueger, F., Zahn, R., Pardini, M., de Oliveira-Souza, R., \& Grafman, J. (2006). Human Fronto-Mesolimbic Networks Guide Decisions About Charitable Donation. Proceedings of the National Academy of Sciences of the United States of America, 103(42), 15623-15628. doi: 10.1073/pnas.0604475103

Montague, P. R., \& Berns, G. S. (2002). Neural Economics and the Biological Substrates of Valuation. Neuron, 36(2), 265-284. doi: 10.1016/s0896-6273(02)00974-1

Morrison, S. E., \& Salzman, C. D. (2010). Re-Valuing the Amygdala. Current Opinion in Neurobiology, 20(2), 221-230. doi: 10.1016/j.conb.2010.02.007

O'Doherty, J., Dayan, P., Schultz, J., Deichmann, R., Friston, K., \& Dolan, R. J. (2004). Dissociable Roles of Ventral and Dorsal Striatum in Instrumental Conditioning. Science, 304(5669), 452-454. doi: 10.1126/science.1094285

O'Doherty, J., Winston, J., Critchley, H., Perrett, D., Burt, D. M., \& Dolan, R. J. (2003a). Beauty in a Smile: The Role of Medial Orbitofrontal Cortex in Facial Attractiveness. Neuropsychologia, 41(2), 147-155.

O'Doherty, J. P., Dayan, P., Friston, K., Critchley, H., \& Dolan, R. J. (2003b). Temporal Difference Models and Reward-Related Learning in the Human Brain. Neuron, 38(2), 329-337.

Olds, J., \& Milner, P. (1954). Positive Reinforcement Produced by Electrical Stimulation of Septal Area and Other Regions of Rat Brain. Journal of Comparative and Physiological Psychology, 47(6), 419-427.

Padoa-Schioppa, C. (2011). Neurobiology of Economic Choice: A Good-Based Model. Annual Review of Neuroscience, 34(1), 333-359. doi: 10.1146/annurev-neuro-061010113648

Pizzagalli, D. A., Holmes, A. J., Dillon, D. G., Goetz, E. L., Birk, J. L., Bogdan, R., Dougherty, D. D., Iosifescu, D. V., Rauch, S. L., \& Fava, M. (2009). Reduced Caudate and Nucleus Accumbens Response to Rewards in Unmedicated Individuals with Major Depressive Disorder. American Journal of Psychiatry, 166(6), 702-710. doi: 10.1176/appi.ajp.2008.08081201

Platt, M. L., \& Glimcher, P. W. (1999). Neural Correlates of Decision Variables in Parietal Cortex. Nature, 400(6741), 233-238. doi: 10.1038/22268

Ramnani, N., Elliott, R., Athwal, B. S., \& Passingham, R. E. (2004). Prediction Error for Free Monetary Reward in the Human Prefrontal Cortex. Neuroimage, 23(3), 777-786. doi: 10.1016/j.neuroimage.2004.07.028 
Rangel, A., Camerer, C., \& Montague, P. R. (2008). A Framework for Studying the Neurobiology of Value-Based Decision Making. Nature Reviews: Neuroscience, 9(7), 545-556. doi: 10.1038/nrn2357

Robbins, T. W., \& Everitt, B. J. (1996). Neurobehavioural Mechanisms of Reward and Motivation. Current Opinion in Neurobiology, 6(2), 228-236. doi:

Rolls, E. T., O'Doherty, J., Kringelbach, M. L., Francis, S., Bowtell, R., \& McGlone, F. (2003). Representations of Pleasant and Painful Touch in the Human Orbitofrontal and Cingulate Cortices. Cerebral Cortex, 13(3), 308-317.

Rutledge, R. B., Dean, M., Caplin, A., \& Glimcher, P. W. (2010). Testing the Reward Prediction Error Hypothesis with an Axiomatic Model. Journal of Neuroscience, 30(40), 1352513536. doi: 10.1523/JNEUROSCI.1747-10.2010

Saxe, R. (2006). Uniquely Human Social Cognition. Current Opinion in Neurobiology, 16(2), 235-239. doi: 10.1016/j.conb.2006.03.001

Schultz, W. (2000). Multiple Reward Signals in the Brain. Nature Reviews: Neuroscience, 1(3), 199-207. doi: 10.1038/35044563

Schultz, W. (2006). Behavioral Theories and the Neurophysiology of Reward. Annual Review of Psychology, 57, 87-115. doi: 10.1146/annurev.psych.56.091103.070229

Schultz, W., Dayan, P., \& Montague, P. R. (1997). A Neural Substrate of Prediction and Reward. Science, 275(5306), 1593-1599.

Schultz, W., \& Dickinson, A. (2000). Neuronal Coding of Prediction Errors. Annual Review of Neuroscience, 23, 473-500. doi: 10.1146/annurev.neuro.23.1.473

Seymour, B., Daw, N., Dayan, P., Singer, T., \& Dolan, R. (2007a). Differential Encoding of Losses and Gains in the Human Striatum. Journal of Neuroscience, 27(18), 48264831. doi: 10.1523/JNEUROSCI.0400-07.2007

Seymour, B., Singer, T., \& Dolan, R. (2007b). The Neurobiology of Punishment. Nature Reviews: Neuroscience, 8(4), 300-311. doi: 10.1038/nrn2119

Small, D. M., Zatorre, R. J., Dagher, A., Evans, A. C., \& Jones-Gotman, M. (2001). Changes in Brain Activity Related to Eating Chocolate: From Pleasure to Aversion. Brain, $124(\mathrm{Pt}$ 9), 1720-1733.

Smith, D. V., Clithero, J. A., Boltuck, S. E., \& Huettel, S. A. (2014). Functional Connectivity with Ventromedial Prefrontal Cortex Reflects Subjective Value for Social Rewards. Social Cognitive and Affective Neuroscience, 9(12), 2017-2025. doi: 10.1093/scan/nsu005

Smith, D. V., Hayden, B. Y., Truong, T. K., Song, A. W., Platt, M. L., \& Huettel, S. A. (2010). Distinct Value Signals in Anterior and Posterior Ventromedial Prefrontal Cortex. Journal of Neuroscience, 30(7), 2490-2495. doi: 10.1523/JNEUROSCI.3319-09.2010

Smith, D. V., \& Huettel, S. A. (2010). Decision Neuroscience: Neuroeconomics. Wiley Interdiscip Rev Cogn Sci, 1(6), 854-871. doi: 10.1002/wcs.73

Stuber, G. D., Britt, J. P., \& Bonci, A. (2012). Optogenetic Modulation of Neural Circuits That Underlie Reward Seeking. Biological Psychiatry, 71(12), 1061-1067. doi: 10.1016/j.biopsych.2011.11.010

Sugrue, L. P., Corrado, G. S., \& Newsome, W. T. (2005). Choosing the Greater of Two Goods: Neural Currencies for Valuation and Decision Making. Nature Reviews: Neuroscience, 6(5), 363-375. doi: 10.1038/nrn1666 
Treadway, M. T., \& Zald, D. H. (2013). Parsing Anhedonia: Translational Models of RewardProcessing Deficits in Psychopathology. Current Directions in Psychological Science, 22(3), 244-249. doi: 10.1177/0963721412474460

Tricomi, E., \& Fiez, J. A. (2012). Information Content and Reward Processing in the Human Striatum During Performance of a Declarative Memory Task. Cognitive, Affective \& Behavioral Neuroscience, 12(2), 361-372. doi: 10.3758/s13415-011-0077-3

Tricomi, E. M., Delgado, M. R., \& Fiez, J. A. (2004). Modulation of Caudate Activity by Action Contingency. Neuron, 41(2), 281-292.

van den Bos, W., Talwar, A., \& McClure, S. M. (2013). Neural Correlates of Reinforcement Learning and Social Preferences in Competitive Bidding. Journal of Neuroscience, 33(5), 2137-2146. doi: 10.1523/JNEUROSCI.3095-12.2013

Vartanian, O., \& Goel, V. (2004). Neuroanatomical Correlates of Aesthetic Preference for Paintings. Neuroreport, 15(5), 893-897.

Vickery, T. J., Chun, M. M., \& Lee, D. (2011). Ubiquity and Specificity of Reinforcement Signals Throughout the Human Brain. Neuron, 72(1), 166-177. doi: 10.1016/j.neuron.2011.08.011

Watson, K. K., Matthews, B. J., \& Allman, J. M. (2007). Brain Activation During Sight Gags and Language-Dependent Humor. Cerebral Cortex, 17(2), 314-324. doi: 10.1093/cercor/bhj149

Winston, J. S., O'Doherty, J., Kilner, J. M., Perrett, D. I., \& Dolan, R. J. (2007). Brain Systems for Assessing Facial Attractiveness. Neuropsychologia, 45(1), 195-206. doi: 10.1016/j.neuropsychologia.2006.05.009

Wise, R. A., Spindler, J., deWit, H., \& Gerberg, G. J. (1978). Neuroleptic-Induced "Anhedonia" in Rats: Pimozide Blocks Reward Quality of Food. Science, 201(4352), 262-264. doi: 10.1126/science.566469

Yarkoni, T., Poldrack, R. A., Nichols, T. E., Van Essen, D. C., \& Wager, T. D. (2011). LargeScale Automated Synthesis of Human Functional Neuroimaging Data. Nat Methods, 8(8), 665-670. doi: 10.1038/nmeth.1635

Zaki, J., Lopez, G., \& Mitchell, J. P. (2014). Activity in Ventromedial Prefrontal Cortex CoVaries with Revealed Social Preferences: Evidence for Person-Invariant Value. Social Cognitive and Affective Neuroscience, 9(4), 464-469. doi: 10.1093/scan/nst005

Zink, C. F., Pagnoni, G., Chappelow, J., Martin-Skurski, M., \& Berns, G. S. (2006). Human Striatal Activation Reflects Degree of Stimulus Saliency. Neuroimage, 29(3), 977-983. doi: 10.1016/j.neuroimage.2005.08.006 


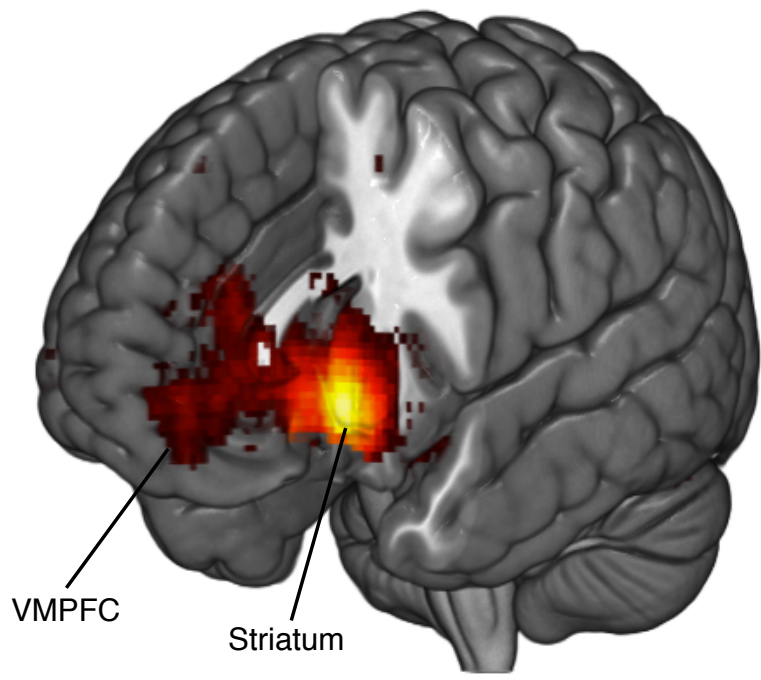

